\title{
ANALISIS PEMBUATAN PIPA BAJA SISTEM DUA BAGIAN LAS ASTM A139 DENGAN MENGGUNAKAN METODA LSAW MANUFACTUR ANALYSIS DUAL SEAM WELD STEEL PIPE ASTM A139 BY USING LSAW METHODE
}

\author{
Djoko W. Karmiadji ${ }^{\text {a) }}$, Gery Setiadi ${ }^{\text {b) }}$ \\ a) Balai Besar Teknologi Kekuatan Struktur - BPPT, Kawasan PUSPIPTEK Gd \\ 220,Serpong, Tangerang 15314 \\ b) PT Elnusa Tbk, JI.T.B. Simatupang Kav.1B Jakarta 12560 \\ e-mail :dkarmiadii@rocketmail.com ,gery.setiadi@elnusa.co.id
}

Tanggal masuk naskah :04/03/2014; Tanggal revisi:01/04/2014; Tanggal persetujuan cetak : 30/05/2014

\begin{abstract}
Abstrak
Salah satu komponen utama dari pembuatan pipa baja adalah baja berupa plat lembaran, slab atau hot roll coil, dimana dari bahan ini dapat dibuat berbagai jenis pipa antara lain pipa seamless, pipa Electric Wire Resistance, pipa Spiral, dan Pipa Longitudinal.

Material utama pipa baja las yang digunakan adalah plat baja atau hot roll coil. Ketergantungan pengadaan material menjadi kendala bagi pabrik pipa baja las, dimana pada saat ini pabrik baja di negara kita belum mampu memproduksi bahan pipa baja berdiameter lebih dari 24" terutama digunakan pada sektor minyak dan gas.

Pada penelitian ini dilakukan analisis pembuatan pipa baja las dengan menggunakan bahan plat lokal yang terdiri dari dua bagian kemudian di las dengan jenis las GMAW dan SMAW, dimana pembuatan pipa baja las dengan dimensi Ø 28" x 8,7 mm x $12.000 \mathrm{~mm}$ dilakukan menggunakan metoda LSAW (Longitudinal Sub Merged Arc Welding). Teknik pengujian dan pemeriksaan dilakukan dengan mengacu pada standar ASTM A139.

Berdasarkan analisis hasil pengujian dan pemeriksaan, dapat di simpulkan bahwa metode pembuatan pipa baja las menggunakan metode dual seam weld longitudinal submerged arc welding memenuhi persyaratan standar sebagaimana yang dipersyaratkan pada standar ASTM A139.
\end{abstract}

Kata kunci: pipa baja, las dua bagian, ASTM A139

\begin{abstract}
One of the main components of the manufacture of steel pipe is in the form of plate steel sheet, slab or hot roll coil, which of these materials may be made for various types of pipes, among others, seamless, Electric Wire Resistance, Spiral and Longitudinal pipes.

The main material used welding steel pipe is a steel plate or hot roll coil. Material procurement dependence becomes an obstacle for welding steel pipe mill, which at this moment in our country's steel mills have not been able to produce material of diameter of 24 "steel pipe used primarily in the oil and gas sector.

In this research, the analysis of welded steel pipe manufacture using local plate material consisting of two sections then welded with GMAW and SMAW welding type, where the manufacture of welded steel pipe with dimensions $\varnothing 28$ "x $8.7 \mathrm{~mm} \times 12.000 \mathrm{~mm}$ is done using the LSAW (Longitudinal Sub Merged Arc Welding) method. Mechanical testing and inspection conducted in accordance with ASTM A139.

Based on the analysis of the results of testing and inspection, it can be concluded that the method of manufacture of welded steel pipes using dual seam weld longitudinal submerged arc welding compliant as required in the standard ASTM A139.
\end{abstract}

Keywords : steel pipe, dual seam weld, ASTM A139 


\section{PENDAHULUAN}

Proses pembuatan pipa baja dalam industri manufaktur dapat dikategorikan kedalam kegiatan proses dan perakitan (assembly), dimana untuk membuat pipa baja berdiameter besar yang memiliki ukuran mulai dari 24" sampai dengan 48" dihasilkan melalui proses pembentukan (shaping procesess) dan pembersihan permukaan (surface processing operation) serta pengelasan (permanent joining processes) [1].

Material pipa baja di buat dari dua bentuk baja, round billet dan slab. Billet adalah baja bulat padat yang dapat digunakan untuk membuat pipa tanpa sambungan (seamless). Sedangkan jenis pipa lainnya dibuat dari slab, yaitu berupa baja yang berbentuk kotak padat memanjang, slab di dipanaskan dan di proses menjadi bentuk lembaran plat dan koil $[2,6]$.

Pada industri minyak dan gas, pipa yang digunakan harus mengacu kepada standar yang berlaku, diantaranya: SNI (Standar Nasional Indonesia); API (American Petroleum Institute); DNV (Det Norske Veritas); ASTM (American Society For Testing and Materia); AWWA (American Water Work Association); ASME (American Society of Mechanical Engineering); AWS (American Welding Society); NACE (National Association of Corrosion Engineer)[7].

Disamping untuk memenuhi persyaratan kemanan dan keselamatan, standar tersebut diatas juga mengatur hal mengenai bagaimana seharusnya proses pembuatan pipa baja dibuat, mulai dari proses pemilihan material, proses pembentukan, proses pengelasan, proses pemeriksaan dan pengujian pipa baik dengan cara tidak merusak (Non Destructive Test) dan cara merusak (Destructive Test), proses pengujian tekanan (hydrostatic test) sampai dengan penandaan pada pipa.

Seiring dengan peningkatan akan kebutuhan pipa diameter besar untuk proyek jaringan distribusi pipa minyak dan gas, beberapa perusahaan yang bergerak dalam industri minyak dan gas kelas dunia melakukan penelitian mengenai material pipa baja, dimana tujuan dari penelitiannya adalah untuk menekan biaya pada pemasangan distribusi jaringan pipa baja. Dengan tebal plat yang kecil diharapkan dapat mengalirkan gas atau fluida yang mempunyai tekanan besar dengan diameter yang sama.

Salah satu metode pembuatan pipa berdiameter besar yaitu dengan dengan metode pengelasan memanjang atau yang lebih dikenal dengan LSAW (Longitudinal Sub Merged Arc Welding) menggunakan bahan berupa lembaran plat baja yang kemudian mengalami proses pembentukan dan pengelasan sampai menjadi bentuk pipa baja sesuai dengan standar yang digunakan.

Keterbatasan bahan baku plat lembaran dalam negeri juga merupakan kendala bagi pabrik pipa dalam negeri untuk dapat melaksanakan kegiatan produksinya terutama untuk pabrik pipa baja yang memproduksi pipa baja berdiameter lebih dari 24". Salah satu pabrik plat baja dalam negeri yang dapat membuat material plat baja coil (HRC) adalah PT. Krakatau Steel Cilegon, ukuran tebal dan lebar maksimum plat yang dapat diproduksi adalah tebal 0.8 sampai dengan $25 \mathrm{~mm}$ dan lebar 600 $2060 \mathrm{~mm}$ ) [5].

Beberapa penelitian telah dilakukan oleh pabrikan pipa baja terhadap material pipa baja, sedangkan dalam penelitian ini dilakukan analisa terhadap satu alternatif pembuatan pipa baja dengan menggunakan material plat dari bahan HRC dengan spesifikasi JIS SS 400 hasil produksi pabrik pipa baja dalam negeri. Proses pembuatan melalui penyambungan dua bagian sisi plat dengan sistem pengelasan dual seam weld, yang kemudian hasil pengelasan ini divalidasi dengan standar ASTM A139 [3], sehingga dapat diketahui apakah metode pengelasan di atas dapat memenuhi standar spesifikasi yang terdapat dalam standar tersebut.

\section{BAHAN DAN METODA}

Penelitian dilakukan dengan membuat pipa baja ukuran 28 ", dimana panjang dan tebal adalah $12 \mathrm{~m} \times 8,7 \mathrm{~mm}$, dengan bahan dasar yang terdiri dari dua lembar plat disambung dengan metoda pengelasan SMAW dan dibentuk menjadi pipa melalui proses pembentukan dan pengelasan seperti yang dilakukan pada pembuatan pipa LSAW.

Pipa disebut dengan pipa longitudinal karena pengelasan yang dilakukan arahnya memanjang, sedangkan bahan yang digunakan adalah lembaran plat dan bukan merupakan gulungan plat seperti pada 
proses pembuatan pipa ERW (Electric Resistance Welding) atau pipa sprial.

Proses pembuatan pipa longitudinal meliputi beberapa tahap proses yang secara garis besar dibagi menjadi tiga bagian, yaitu: forming atau pembentukan; welding; dan pengujian dan pemeriksaan $[8,9,10]$.

Proses pembentukan pipa longitudinal dikenal dua metoda pembentukan, yaitu dengan UOE proses dan Three Roll Bending. Istilah ini berasal dari nama jenis mesin yang digunakan untuk proses pembentukan pipa. Perbedaan dari kedua jenis proses pembentukan ditunjukkan pada gambar 1. Proses pembentukan pipa. Sedangkan alur proses pembuatan pipa ditunjukkan pada gambar 2 .
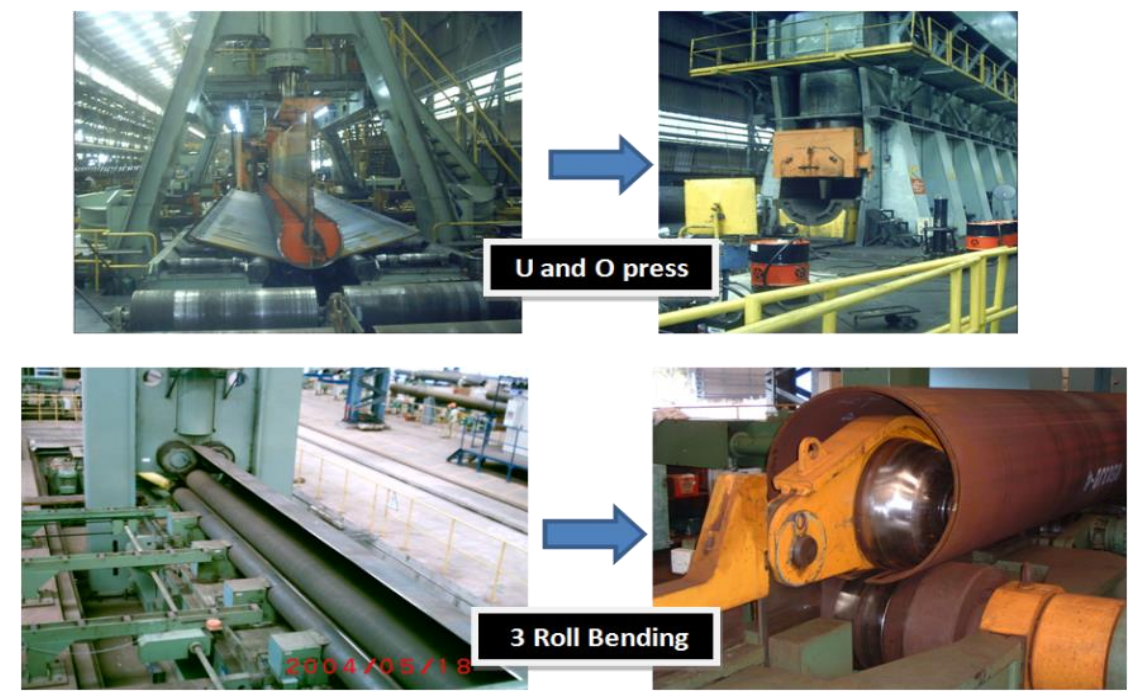

Gambar 1: Proses pembentukan pipa.
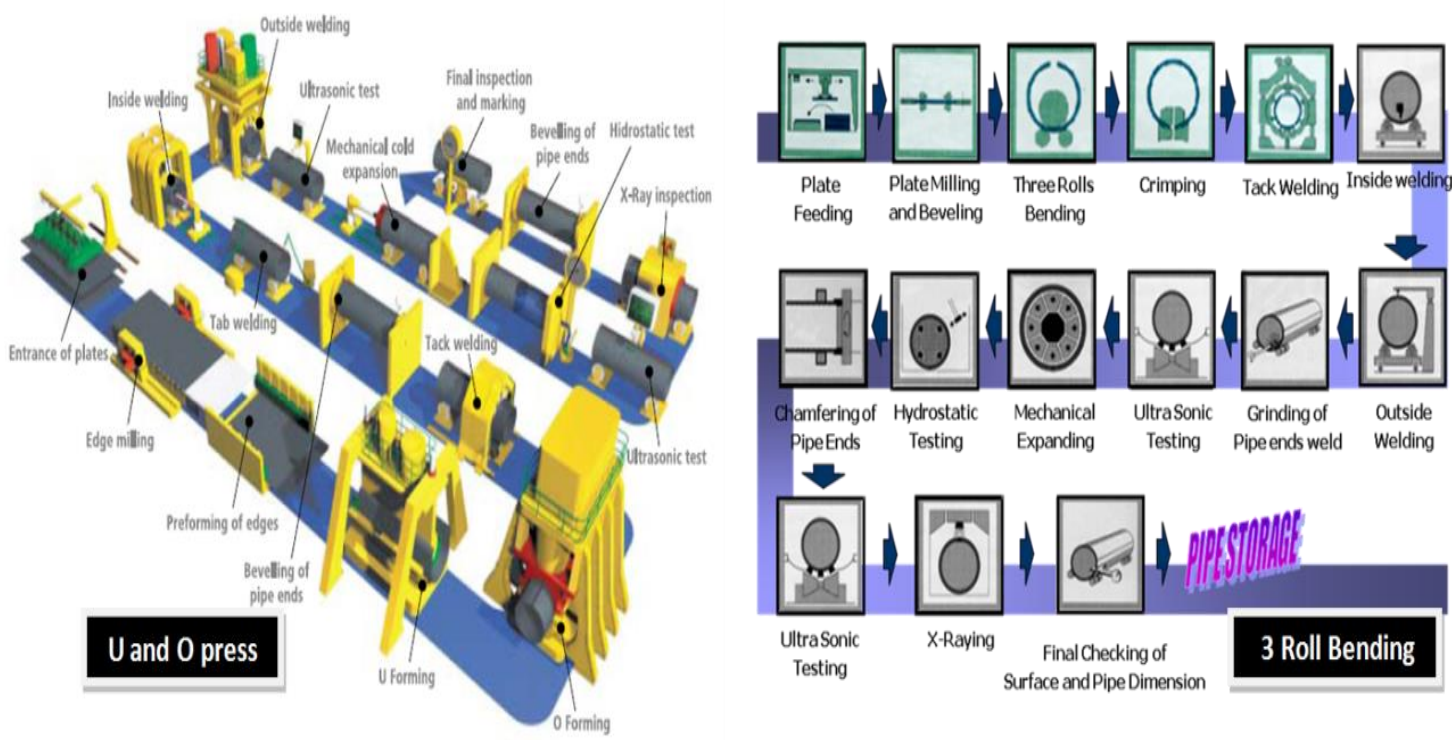

Gambar 2 : Alur proses pembuatan pipa.

Pipa baja dibuat mengacu kepada standar ASTM A-139 dimana pada standar tersebut tercantum kandungan komposisi kimia dan karakteristik mekanis pipa. Hasil pengelasan pipa baja selanjutnya diuji dan diperiksa untuk untuk memastikan apakah pipa yang dibuat memenuhi standar yang ditetapkan agar dapat dengan aman digunakan . 
Jenis pengujian dan pemeriksaan pada logam dibagi kedalam pengujian merusak (Destructive Test) dan pengujian tidak merusak (Non Destructive Test), yang termasuk kedalam pengujian merusak antara lain:

- Pengujian mekanik

- Uji tarik (tensile)

- Uji tekuk (guided bend test)

- Uji takik (V-notch)

- Uji kekerasan

- Uji metalografis

- Pengujian makro

- Pengujian mikro

- Analisis kimia

Sedangkan 6 jenis pemeriksaan dan pengujian tidak merusak yang sering dilakukan adalah sebagai berikut:

- Visual inspection

- Liquid penetrant

- Magnetic

- Ultrasonic

- Eddy current

- X-Ray

Benda uji untuk uji mekanis diambil dari pipa yang telah melalui proses mechanical expander, untuk pipa jenis ini prosedur tes dan pengambilan sampel harus sesuai dan mengacu kepada standar A 370 Test Methodes and Definition for Mechanical Testing of Steel Product [4], karena pada penelitian ini yang akan dikualifikasi adalah pembuatan pipa baja las berdasarkan welding prosedur yang dibuat dan bukan terhadap pipa produksi masal, maka pengujian dilakukan dengan mengacu pada ASME Boiler and Pressure Vessel Code, Section IX.

\section{HASIL DAN PEMBAHASAN}

Hal - hal yang berkaitan dengan persiapan proses las, baik las pada plat maupun pada pipa adalah tersedianya dokumen-dokumen yang berkaitan dengan proses pengelasan. Seperti diatur dalam ASME setion IX [5] bahwa setiap pabrik atau kontraktor harus menyiapkan dokumen dokumen seperti Welding Procedure Specifications (WPS); Welding Operator Qualification; dan Procedure Qualification Record.

Analisis pembuatan pipa baja las dengan menggunakan bahan dua plat disambung dengan metode las dual seam weld, dimulai dari proses penggabungan plat dengan las, pembentukan plat menjadi pipa, pengelasan pada pipa sampai pada tahap pengujian dan pemeriksaan pipa.
Agar proses penggabungan plat dengan las berhasil dengan baik, maka sisi kedua plat dibuat sudut/bevel dengan menggunakan cutting torch atau gerinda, besar sudut harus mengacu pada WPS. Kemudian dilakukan clamping dan diberi beban pada plat dengan menggunakan plat pemberat yang berat masing-masing minimum 20 ton, agar plat tidak melengkung pada saat pengelasan. Saat pengelasan tahap dua, plat dibalik dengan menggunakan alat pembalik plat manual. Pengelasan tahap dua sama seperti dengan tahap satu namun harus dipastikan hasil lasan permukaan las tahap satu harus sejajar dengan permukaan plat. Selanjutnya dilakukan pembentukan pipa seperti ditunjukkan pada gambar 1 .

Pengelasan dimulai dengan tack weld yaitu pengelasan pertama yang berfungsi untuk mengikat dua sisi plat sebelum menuju pengelasan berikutnya, sekaligus dilakukan pemasangan tab (gambar 3). Selanjutnya dilakukan pengelasan di bagian dala dan luar pipa seperti pada gambar 4.

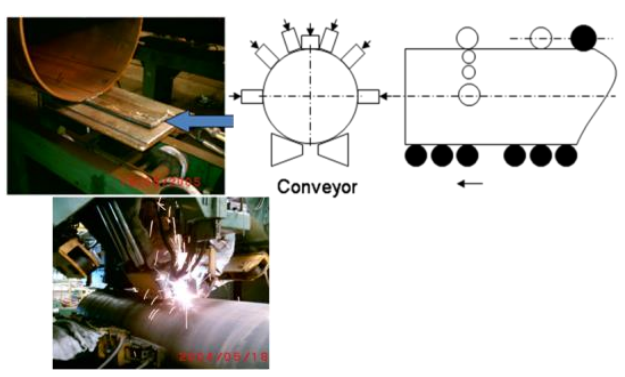

Gambar 3 : Tack weld

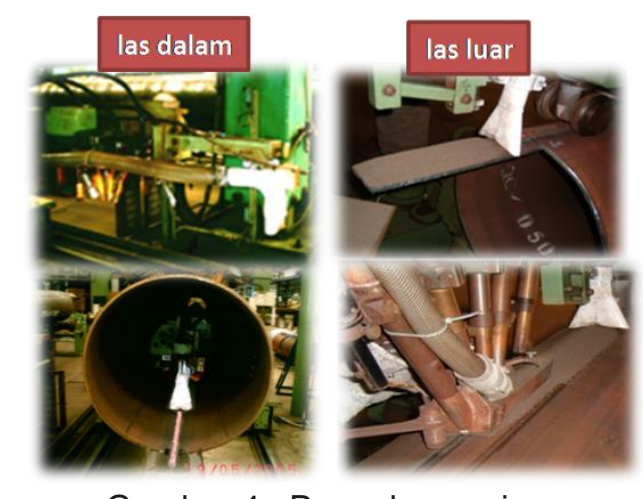

Gambar 4 : Pengelasan pipa.

Pengisian las dengan menggunakan las semi auto SMAW dengan parameter sesuai dengan WPS dan kampuh hasil lasan digerinda hingga sejajar dengan permukaan plat (gambar 5). 


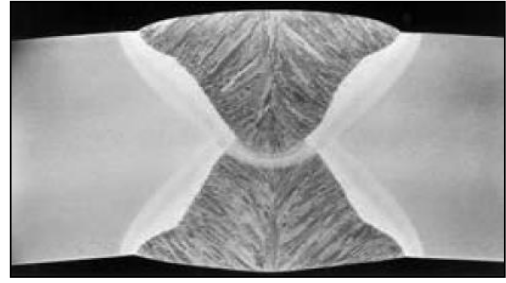

Gambar 5 : Penampang las pipa

Pemeriksaan las dilakukan secara visual dan menggunakan magnetic particle inspection, dimana proses diteruskan jika tidak ditemukan cacat lasan pada daerah sekitar las dan logam metal (gambar 6).

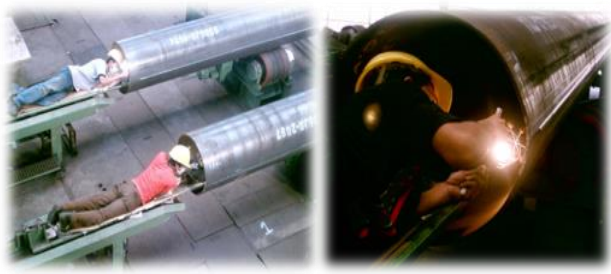

Gambar 6 : Inpseksi hasil las.

Uji hidrostatis dilakukan pada pipa yang sudah jadi dengan memasukkan air hingga nilai tekanan tertentu dan di tahan selama periode tertentu yang hasilnya di catat secara otomatis (gambar 7). Tekanan yang diberikan pada pipa adalah sesuai dengan formula dibawah :

$$
P=\dot{2} \frac{S t}{D}
$$

$P=$ Tekanan $(\mathrm{MPa})$

$S=$ Stress factor $=75 \%$ SMYS (Specified Minimum yield strength $=250 \mathrm{Mpa}$ ) $=187,5 \mathrm{MPa}$

$t=$ Tebal $(=8,7 \mathrm{~mm})$

$D=$ Diameter luar $(=711 \mathrm{~mm})$

Dengan parameter diats maka tekaanan $P=$ $4,5 \mathrm{MPa}=45 \mathrm{Bar}$, yang diberikan selama 10 menit.

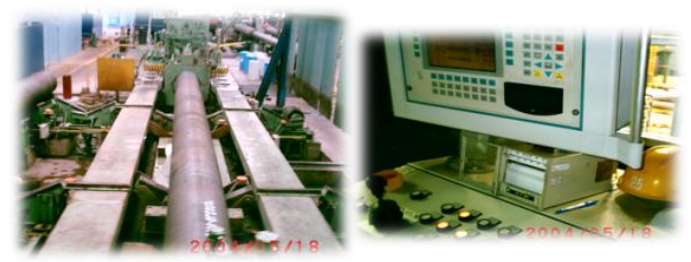

Gambar 7 : Hydrotester

Agar pemasangan di lapangan tidak sulit, maka pipa yang sudah di uji hydrostatis diberi perlakuan end chamfering yaitu pembuatan sudut pada kedua sisi ujung pipa, dimana sudut yang dibuat disesuaikan dengan permintaan atau berdasarkan standar (gambar 8). Sudut yang dibentuk sebesar $30^{\circ}$ dengan root face $1.6 \mathrm{~mm}$.

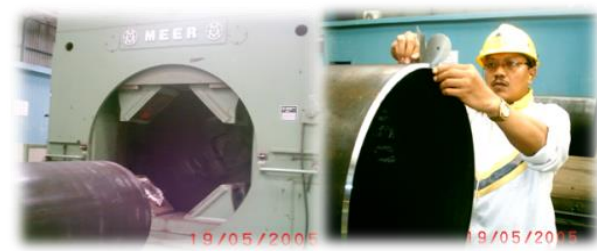

Gambar 8 : End chamfering

Pembuatan sample dan metode pengujian mengacu kepada standar ASTM A 370, dimana pengujian tarik dan tekuk dilakukan dengan menggunakan mesin uji universal (gambar 9).

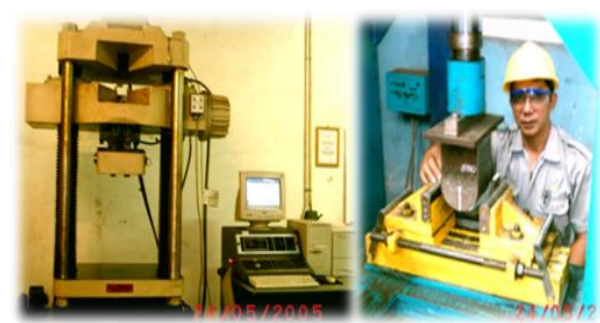

Gambar 9 : Mesin uji universal

Ketentuan dalam pengujian tarik adalah nilai kekuatan tarik tidak boleh kurang dari $100 \%$ nilai minimum specified tensile strength grade material yang digunakan [5], dalam hal ini spesifikasi material yang dimaksud adalah JIS SS 400 dengan nilai kekuatan tarik minimum sebesar $400 \mathrm{MPa}$. Dari hasil pengujian didapat nilai kekuatan tarik pada kedua daerah las untuk las manual adalah sebesar $488 \mathrm{MPa}$ dan $485 \mathrm{Mpa}$, untuk las auto sebesar $484 \mathrm{MPa}$ dan $514 \mathrm{MPa}$ sedangkan nilai minimum yang ditetapkan adalah sebesar $330 \mathrm{MPa}$, sehingga pengujian dapat diterima.

Ketentuan pada uji tekuk adalah tidak terdapat retak yang melebihi 3,2 $\mathrm{mm}$ setelah ditekan [5]. Pengujian dilakukan dengan mengacu pada standar, dimana keempat specimen yang diuji terdapat retak pada face bend 1, namun jarak panjang retak yang terjadi sebesar $0,9 \mathrm{~mm}$ pada las auto dan $0,8 \mathrm{~mm}$ pada las manual, sehingga masih masuk dalam nilai toleransi.

Dari hasil uji makro baik pada hasil lasan yang menggunakan mesin las otomatis maupun manual, masing - masing ditunjukkan pada gambar 10, dimana terlihat tidak terdapat cacat pada lasan, begitu juga pada penetrasi lasan pada bagian dalam dan luar juga tidak menyimpang. 


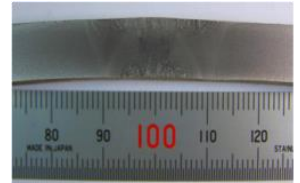

las manual

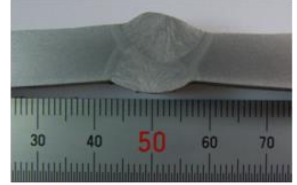

las otomatis
Gambar 10 : Hasil uji makro

Hasil pengujian komposisi kimia dengan menggunakan mesin spektrometer (gambar 11) menunjukan masing-masing kandungan $\mathrm{C}, \mathrm{Mn}, \mathrm{P}$ dan $\mathrm{S}$, dimana kandungan komposisi masing - masing komponen yang diuji tidak melebihi nilai maksimum. Hasil pengujian komposisi kimia menunjukkan kandungan C 0,17\% $\% 0,28$ $\% ;$ Mn 1,13\% < 1,20\%; P 0,012 \% < 0,035 $\%$; dan S 0,003 \% < 0,035.

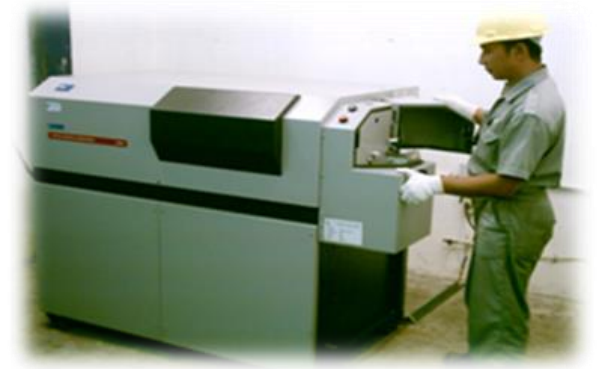

Gambar 11 : Mesin Spektometer
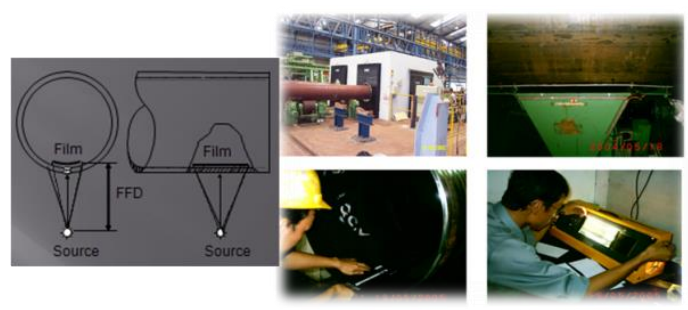

Gambar 12 : Pengujian X-ray

Pengujian non-destruktif dilakukan pada daerah yang menggunakan las manual dan daerah yang menggunakan las auto, dengan jarak penembakan antara $0-60 \mathrm{~cm}$ dari ujung pipa. Hasil pengujian dengan mesin X-ray menunjukan bahwa tidak terdapat cacat las pada daerah las dan pengujian dapat diterima.

\section{KESIMPULAN}

Berdasarkan analisis pembuatan pipa baja dengan menggunakan metode pengelasan dual seam weld dengan cara pengelasan manual dan otomatis maka WPS pembuatan pipa las baja dengan menggunakan metode dual seam weld dapat dilakukan dan memenuhi persyaratan pada standar ASTM A-139.
Secara ekonomis pengelasan dengan menggunakan metode ini jelas memerlukan biaya dan waktu yang lebih besar, bahan baku las seperti wire dan flux membutuhkan konsumsi yang lebih banyak dibandingkan dengan pengelasan biasa. Namun apabila dilihat dari sisi ketersedian bahan baku terutama bahan baku kandungan lokal maka hal ini sangat menguntungkan dapat membantu meningkatkan utilisasi pabrik pipa yang ada serta profit.

Perlunya dilakukan percobaan dengan menggunakan mesin las semi auto dalam penggabungan plat dan mecari besar sudut optimum pada sisi plat sehingga pengelasan dapat dilakukan dengan lebih cepat dan penggunaan konsumabel las berupa wire dan flux dapat dikurangi dan serta kualitas las yang baik dapat dengan mudah dicapai.

Penelitian lebih lanjut mengenai berapa jumlah plat yang dapat di gabung serta berapa dimensi pipa yang dapat dibuat dengan menggunakan metode dual seam weld perlu dilakukan, sehingga dapat memperluas market serta meningkatkan utilisasi pabrik pipa baja dan dapat dijadikan sebagai salah satu alternatif solusi dari keterbatasan pengadaan material.

\section{DAFTAR PUSTAKA}

1. Groover M.P, "Fundamentals of Modern Manufacturing: Materials, Processes, and Systems", John Wiley \& Sons, 2010.

2. Bill Buckland, " An Introduction into the production and specification of steel plate pipe", Pile Driver 2005

3. ASTM A139 - 04, Standard Specification for Electric-Fusion (Arc)-Welded Steel Pipe (NPS 4 and Over), 2010

4. ASTM A370 - 14, Standard Test Methods and Definitions for Mechanical Testing of Steel Products Annual Book of ASTM Standards, Section one, Vol. 01.01, 2005

5. ASME Boliler \& Presuure Vessel code section IX, 2004

6. Wiryosumarto, H., Okumura, T., "Tekno-logi Pengelasan Logam ", Pradnya Paramita, 2008 
7. ANSI/API Specification 5L, 44 edition, October,1,2007

8. Brensing, K-H., Sommer, B., Steel Tube and Pipe Manufacturing Processes, http://www.smrw.de/files/steel_tube _and_pipe.pdf, 20-11-2014

9. Masamura, K., Nagahama, Y., Manufac-turing Processes and
Products of Steel Pipes and Tubes in JFE Steel, JFE Technical Report, No. 7 (Jan. 2006)

10. Nippon Steel \& Sumitomo Metal, Seamless Steel Line Pipe, http:// www.nssmc.com/product/catalog_d ownload/pdf/P103en.pdf, 20-112014 